\title{
$140 \mathrm{k}$ vs $40 \mathrm{k}$ ! Does this journal need short papers?
}

\author{
Yizhou Miao $^{1}$ (D) Yuehong Zhang $^{1}$ (B) \\ Received: 1 January 2022 / Accepted: 5 January 2022 / Published online: 7 February 2022 \\ (c) Zhejiang University Press 2022
}

\section{What does $140 \mathrm{k}$ versus $40 \mathrm{k}$ reveal?}

It has been reported, using Scopus data, that the number of short papers (also known as "non-source items" in the Web of Science) published in the United States in 2020 was about 140,000 (about $18.5 \%$ of its total publication). The corresponding number to appear in China was only about 40,000 (about 5.6\%) [1]. It is also noteworthy that the world's leading academic journals (e.g., Science, Nature, and $P N A S$ ) have relatively long histories when it comes to publishing short papers, mainly Editorials, Opinions, News pieces, and Letters. We therefore took Nature as an example and listed the article types (or column headings) seen in its foundation year as well as in a recent issue (Table 1). This simple analysis shows that while several classic types have always been in use, some have been renamed over time in order to adapt to scientific developments of the last 150 years. It is noteworthy that the different kinds of short papers published in Nature have remained more-or-less stable over recent years (Table 1).

We make the following observations regarding recent issues of the three leading scientific journals: (1) Nearly half of all published articles in Science comprise short papers, about $30 \%$ of total pages; (2) More than $50 \%$ of articles in Nature comprise short papers, about $25 \%$ of pages; (3) Short papers comprise a much lower proportion in PNAS but this journal's use of columns is really interesting. We therefore conclude that while these leading academic journals are interested in publishing different types of short papers, regular articles still do comprise a large majority of each issue in terms of pages.

Yizhou Miao

miaoyizhou@zju.edu.cn

1 Editorial Office of Bio-Design and Manufacturing, Zhejiang University Press, Hangzhou 310028, China
Table 1 A comparison of article types published in Nature in 1869 and 2021

\begin{tabular}{|ll|}
\hline Article type in 1869 [2] & Article type in 2021 (Vol 600, Iss 7889, Dec. 16, 2021) \\
\hline Editorial & This Week \\
Lead Article(s) & Editorial \\
Book Reviews & World View \\
Articles & Research Highlights \\
Letter & News in Focus \\
Notes & News Round-Up \\
Scientific Serials & News \\
Discipline Reports & Features \\
Correspondence & Books \& Arts \\
Societies \& Academies & Book Review \\
Miscellany & Opinion \\
Diary & Comment \\
Books Received & Correspondence \\
& Work \\
& Column \\
& Where I Work \\
& Research \\
& News \& Views \\
& Reviews \\
& Perspective \\
& Articles \\
& Matters Arising \\
& Amendments \& Corrections \\
& Nature Outline \\
\hline The types of short papers (without abstract) seen in a 2021 issue are in red \\
&
\end{tabular}

\section{Short papers have scientific significance}

It is generally believed that in order to prepare a full-length paper, researchers will usually need to spend a relatively long time proposing motivations, reviewing literature, designing methods, carrying out experiments, analyzing statistics, and drawing conclusions. An acceptable, or solid, piece of research may eventually emerge after hundreds or thousands of failures. We should also acknowledge that sometimes a novel but rough idea is also promising, the timely publication of which might even change the world. This could then help researchers both in the same and related fields discover new things.

An earlier example, "On the Origin of Species," is noteworthy as one of the most famous pieces of scientific work of all time. This work was written by Charles Robert Darwin, first published in November 1859 in London. Far fewer col- 


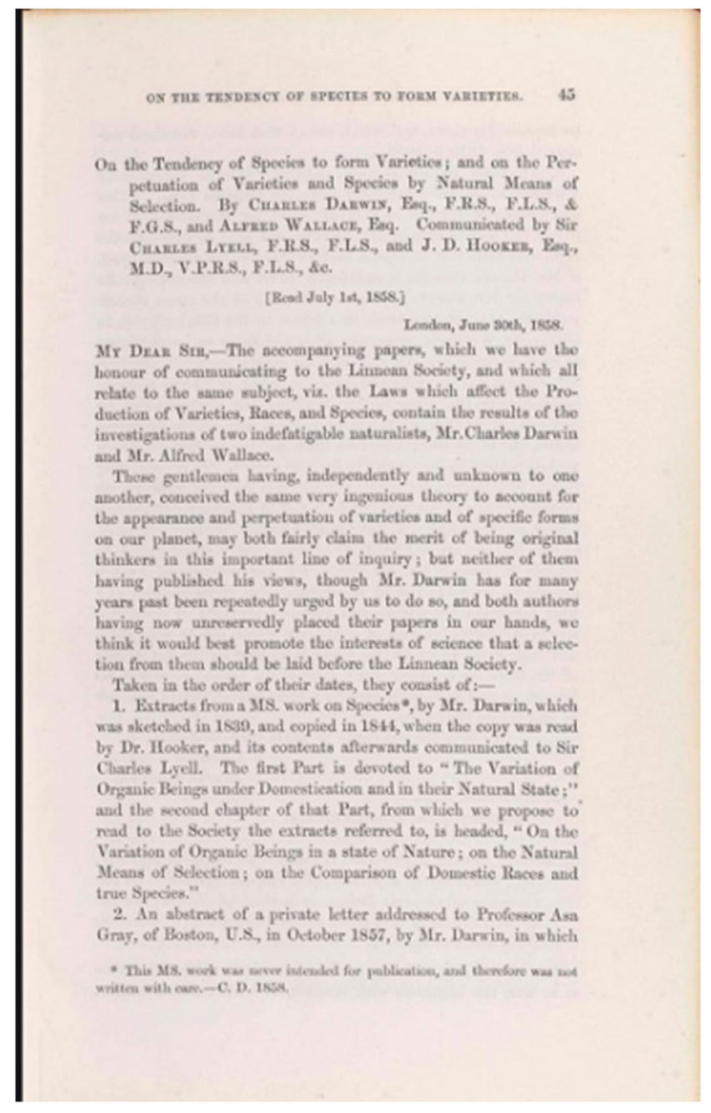

Fig. 1 The letter that first presented Darwin's theory of evolution by natural selection which was published in The Proceedings of the Linnaean Society of London in 1858. This was one year earlier than the publication of the famous "On the Origin of Species" in 1859

leagues, however, will be familiar with the fact that one year earlier, in 1858, a Letter "On the tendency of species to form varieties; and on the perpetuation of varieties and species by natural means of selection" was first published in The Proceedings of the Linnaean Society of London. This short article was actually the place where Darwin first presented his theory of evolution by natural selection (Fig. 1). This initial short article can therefore be regarded as the antecedent of Darwin's famous 1859 work. Additional recent examples, such as two editorials [3, 4], written by Dr. Thorp, the Editorin-Chief of Science, have attracted a lot of attention and resonance. Indeed, a number of scientists commented that this piece [3] "is a timely editorial," which makes us realize "science is a human endeavor with all the frailty of human endeavor."

We therefore argue that existence of short papers (e.g., Letters) in the early days of academic endeavors may have a specific historical background in Western publishing. It is also clear that continuity in the publication of such short papers up until the present day also serves to validate their special scientific value.

\section{Our journal, Bio-Design and Manufacturing $(B D M)$, is striving to improve different types of short papers}

The journal $B D M$ has published short papers since its foundation. Indeed, keeping in mind the great disparity between China and the United States in terms of these articles and considering the particular contribution of short papers, $B D M$ encourages novel ideas, methodologies, and techniques for rapid publication as short papers. This enables $B D M$ to broadcast valuable knowledge to the world. We are therefore also trying to enrich the range of these article types; indeed, as stated in SpringerLink (https://www.springer.com/ journal/42242), BDM currently accepts short papers including Editorials, News \& Views, Perspectives, Letters, Products \& Materials, Technical Notes, Case Reports, Lab Reports, etc. Building on the instructions for authors as presented in Science, Nature, and PNAS [5-7], we also wish to define each kind of short article for $B D M$ and therefore make our content more accessible and useful for authors, reviewers, and readers. We therefore provide clear definitions and page limits, as well as examples of each kind of short paper (Table 2). These types of short papers are all published in BDM without abstracts, and we also ask that the extent of author lists as well as the number of corresponding affiliations should be limited.

All the short papers that we publish in $B D M$ are subjected to rigorous review under either editorial team or via peer-reviewers, guaranteeing their scientific robustness. As short papers may include preliminary conclusions, or sometimes just "speculations," the current peer-review process might "stifle innovation." One relatively new idea across our industry considers a "divide between speculation and "actual science' just on the basis of approval by a small group of anonymous referees" [20]. Thus, due to the unique contribution of short papers, we believe that combining this idea in the peer-review process will lead to a clearer understanding for both authors and reviewers.

As science and technology develops, we believe that biodesign and manufacturing has a promising future. We are therefore always updating our journal's article types, keeping pace with trends in related fields. 
Table 2 Definition of short paper types for $B D M$

\begin{tabular}{|c|c|c|c|}
\hline Article type & Definition & Page limit & Example \\
\hline Editorials & $\begin{array}{l}\text { An editorial is usually solicited. This article type might be written by invited experts from a } \\
\text { specific field summarizing a special issue, or it might be written by editors to report brief but } \\
\text { important materials which we wish to share with readers. An editorial should be a } \\
\text { prospective view that is also timely or with a clear humanistic edge. }\end{array}$ & $\sim 2-3$ pages & {$[3,4,8]$} \\
\hline Perspectives & $\begin{array}{l}\text { A perspective "should identify a critical science problem, provide a state-of-the-art } \\
\text { assessment, and offer new insights or a new approach to its resolution" [5], usually from a } \\
\text { personal view point. }\end{array}$ & $\sim 3-6$ pages & {$[9,10]$} \\
\hline Letters & $\begin{array}{l}\text { A letter is "a short report of original research focused on an outstanding finding whose } \\
\text { importance means that it will be of interest to scientists in other fields" [6]. }\end{array}$ & $\sim 2-3$ pages & {$[11]$} \\
\hline Technical Notes & $\begin{array}{l}\text { A technical note usually "gives a brief description of a specific development, technique or } \\
\text { procedure, or presents a software tool or an experimental or computational method" [12] } \\
\text { with great novelty and (potential) practical value. }\end{array}$ & $\sim 3-5$ pages & {$[13]$} \\
\hline News \& Views & $\begin{array}{l}\text { This kind of article "informs non-specialist readers about new scientific advances" [7] that } \\
\text { have recently been published in } B D M \text { or another journal with similar scope. }\end{array}$ & $\sim 2-3$ pages & {$[14,15]$} \\
\hline Products \& Materials & $\begin{array}{l}\text { This kind of article introduces advanced materials and products that would significantly } \\
\text { influence the development trend in related fields, briefly showing the ingredients, operation, } \\
\text { and the corresponding novelty (a key picture is required). }\end{array}$ & $\sim 1-2$ pages & {$[16]$} \\
\hline Case Reports & $\begin{array}{l}\text { A case report usually "describes patient cases which are of particular interest due to their } \\
\text { novelty and their potential message for clinical practice" [17]. In the case of such papers } \\
\text { submitted to this journal, engineering (mainly bio-design and manufacturing) techniques } \\
\text { should be applied. Much attention should be paid to the comprehensiveness of clinical } \\
\text { information, completeness of course of illness, and accuracy of diagnosis. Due to its specific } \\
\text { characteristics, Informed Consent Form is required in addition to the privacy protection of } \\
\text { patients. }\end{array}$ & $\sim 3-5$ pages & \\
\hline Lab Reports & $\begin{array}{l}\text { A lab report introduces famous labs related to } B D M \text { 's scope in both domestic and overseas, } \\
\text { illustrates research directions to readers, and highlights advanced equipment and key } \\
\text { research groups. }\end{array}$ & $\sim 2-3$ pages & {$[18]$} \\
\hline Negative Results & $\begin{array}{l}\text { A negative result shows an unexpected conclusion based on one's anticipation; most } \\
\text { importantly, it would warn peers "what does not work," avoiding wasting time but trying } \\
\text { another path [19]. }\end{array}$ & $\sim 2-3$ pages & \\
\hline
\end{tabular}

\section{References}

1. Scimago Journal \& Country Rank. https://www.scimagojr.com/ countryrank.php?year=2020. Accessed 26 Dec 2021

2. Zhang YH, 2020. Casting Nature: what have seven male editors done in 150 years of history? (in Chinese). https://zhishifenzi.blog. caixin.com/archives/222533. Accessed 26 Dec 2021

3. Thorp HH (2021) Self-inflicted wounds. Science 374(6569):793. https://doi.org/10.1126/science.abn 1244

4. Thorp HH (2021) It's not as easy as it looks. Science 374(6575):1537. https://doi.org/10.1126/science.abn7633

5. PNAS. https://www.pnas.org/authors/submitting-yourmanuscript\#article-types. Accessed 26 Dec 2021

6. Nature. https://www.doc88.com/p-193328601462.html. Accessed 26 Dec 2021

7. Nature. https://www.nature.com/nature/for-authors/other-subs. Accessed 26 Dec 2021

8. Zhang YS, Khademhosseini A (2020) Engineering in vitro human tissue models through bio-design and manufacturing. Bio-des Manuf 3(3):155-159. https://doi.org/10.1007/s42242-020-00080$\mathrm{W}$

9. Huang X, Yang J, Huang S et al (2021) Minimally invasive technology for continuous glucose monitoring. Bio-des Manuf. https:// doi.org/10.1007/s42242-021-00176-X

10. van Derleun AM, Schumacher TN (2021) An atlas of intratumoral T cells. Science 374(6574):1446-1447. https://doi.org/10. 1126/science.abm9244
11. McGrew WC (2021) Cultural diffusion occurs in chimpanzees. PNAS 118(51):e2116042118. https://doi.org/10.1073/ pnas. 2116042118

12. Ng KH, Peh WCG (2010) Writing a technical note. Singapore Med J 51(2):101-103 (PMID:20358146)

13. Xie M, Zheng Y, Gao Q et al (2021) Facile 3D cell culture protocol based on photocurable hydrogels. Bio-des Manuf 4(1):149-153. https://doi.org/10.1007/s42242-020-00096-2

14. Ma L (2021) Industry news: 2020 high-impact publications in the BDM area. Bio-des Manuf 4(1):154-156. https://doi.org/10.1007/ s42242-020-00123-2

15. He Y (2021) Biomanufacturing: from biomedicine to biomedicine. Bio-des Manuf 4(4):912-913. https://doi.org/10.1007/s42242021-00161-4

16. New products, 2021. Science, 374(6573):1404. https://doi.org/10. 1126/science.acx9756

17. Papanas N, Lazarides MK (2008) Writing a case report: polishing a gem? Int Angiol 27(4):344-349 (PMID:18677298)

18. Gao L, Zhang B, Ma L et al (2018) Research lab on 3D bioprinting of Zhejiang University. Bio-des Manuf 1(3):211-214. https://doi. org/10.1007/s42242-018-0016-Z

19. Journal of Trial and Error, the Netherlands. https://www.jtrialerror. com. Accessed 26 Jan 2022

20. Baldwin M (2021) To reform peer review, we need to understand its past. Nat Rev Phys 3:600-601. https://doi.org/10.1038/s42254021-00354-x 